$\mathrm{mg})$. A recent trial of short term use in patients who have had acute myocardial infarctions has shown that $160 \mathrm{mg}$ aspirin daily reduces mortality after five weeks by a fifth. ${ }^{9}$ Despite the lack of evidence from clinical trials many patients with transient ischaemic attack and stroke are treated with $75 \mathrm{mg}$ daily (a dose enshrined in the current British National Formulary), with the risk that they may be receiving an inadequate dose, albeit a safe one. On the basis of properly conducted clinical trials patients with transient ischaemic attacks and minor ischaemic strokes and no previous problems of peptic ulceration should be treated with $300 \mathrm{mg}$ aspirin daily. The dose may be reduced to $150 \mathrm{mg}$ and then $75 \mathrm{mg}$ if gastrotoxicity is a problem since gastrotoxicity is related to dose. ${ }^{+}$

Aspirin is therefore not a panacea for every patient with a suspected stroke or an undiagnosed "funny turn." But if used in the correct dose in patients with definite transient ischaemic attacks or ischaemic stroke proved by computed tomography it is one of the several effective forms of secondary prevention.

Senior Lecturer,

PETER SANDERCOCK

Department of Clinical Neurosciences,

Western General Hospital,

Edinburgh EH4 2XU
1 Antiplatelet Trialists' Collaboration. Secondary prevention of vascular disease by prolonged antiplatelet treatment. Br Med f 1988;296:320-31.

2 Dennis MS, Bamford JM, Molyneaux A, Warlow CP. Rapid resolution of primary intracerebral haematoma on computed tomograms of the brain. BrMed f 1987;295:379-81.

3 King's Fund Forum. Consensus conference: treatment of stroke. Br Med f 1988;297:126-9.

4 Steering Committee of the Physicians' Health Study Research Group. Preliminary report: finding from the aspirin component of the ongoing Physicians Health Study. $N$ Engl $q$ Med 1988;318:262-4.

5 UK-TIA Study Group. United Kingdom transient ischaemic attack (UK-TIA) trial: interim results. Br Med f 1988;296:316-20.
6 McMahon S, Culter JA, Furberg CD, Payne GH. The effects of drug treatment for hypertension on morbidity and mortality from cardiovascular disease: a review of the randomised controlled trials. Prog Cardiovasc Dis 1986;29(suppl 1):99-118.

7 Peto R, Yusuf S, Collins R. Cholesterol lowering trial results in their epidemiologic context. Circulation 1985;72(III):451.

8 The Dutch TIA Study Group. The Dutch TIA trial: protective effects of low-dose aspirin and atenolol in patients with TIA or non-disabling stroke. Stroke 1988;19:512-7.

ISIS-2 (second international study of infarct survival) Collaborative Group. Randomised trial of intravenous streptokinase, oral aspirin, both, or neither in 17189 cases of suspected acute myocardial infarction: ISIS-2. Lancet 1988 ;ii:349-60.

\title{
Acute failure of artificial heart valves
}

\section{The risk is small}

The recent withdrawal from the market of a mechanical heart valve has once again focused attention on the imperfect nature of substitutes for heart valves. ${ }^{1}$ Reassurance can and should be given, however, to patients with heart valves that such acute failures are exceedingly rate.

Over 5000 artificial heart valves are implanted each year in Britain. Though the incidence of rheumatic fever and chronic rheumatic valvular disease has decreased substantially, overall numbers of valve replacements have been maintained by the increasing incidence of degenerative valve disease in an aging population. The change in the type of diseases in the valves combined with awareness of the imperfections of artificial heart valves have encouraged cardiac surgeons to carry out whenever possible conservative operations that avoid implanting artificial valves. The impressive work of Carpentier et al in France and Cosgrove et al in the United States has shown what can be achieved with conservative operations. ${ }^{2}{ }^{3}$ In Britain, however, only about $12 \%$ of operations on mitral valves and $1-2 \%$ of those on aortic valves are conservative. Conservative operations are favoured for the tricuspid valve, but few such procedures are performed.

Most British patients thus have a diseased valve replaced by an artificial valve-either a mechanical valve (manufactured from totally synthetic materials) or a tissue or bioprosthetic valve (using biological tissue). In 1986 over half (54\%) of all artificial valves implanted in Britain were mechanical. In 1987 this figure rose to almost two thirds (63\%).

The operative mortality of valve replacements has fallen steadily over the past decade. Overall it is now around $5 \%,{ }^{4}$ and even when two or three valves are replaced at the same operation the operative mortality is only $8-11 \%$. Medium and long term mortality and morbidity reflect both the intrinsic imperfections of artificial valves and the inevitable pathological complications associated with implanted artificial valves (infective endocarditis, thromboembolism, and haemorrhage related to anticoagulants) that are not primarily associated with dysfunction of the valve mechanism. Endocarditis, thromboembolism, and haemorrhage related to anticoagulants each occur about one to four times for each 100 patient years of follow up. ${ }^{5}$ These incidences are accepted as the non-preventable consequences of implanting artificial valves.

By contrast, acute failure of the mechanism of an artificial valve is rare, particularly for mechanical valves made from totally synthetic materials. Tissue of bioprosthetic heart valves undergo progressive tissue degeneration rather than sudden failure. The most recent valve failures have been with the Edwards-Duromedics bileaflet valve and the Medtronic Hall single leaflet valve. The Duromedics valve fails because a leaflet escapes whereas in the Medtronic valve the leaflet fractures. Embolisation of the leaflet or part of the leaflet may occur and severe valve regurgitation immediately develops. The sequence is similar to that seen in the acute failure of Bjork-Shiley disc valves reported in 1983, in which fracture of one of the metal struts in the valve ring allowed the valve leaflet to escape.

The Duromedics valve fails 0.04 times in every 100 patient years, whereas the Medtronic valve has failed only three times, although 30000 have been implanted. Patients are thus up to 100 times more likely to develop infective endocarditis, thromboembolism, and haemorrhage related to anticoagulants than to sustain acute mechanical failure of the valve. These data should not, however, encourage complacency. Acute failure of a mechanical valve carries a high immediate mortality; only about a third of patients have survived a strut fracture of the Bjork-Shiley valve. ${ }^{6}$ So far half of the patients have survived an escape of the Duromedics valve leaflet and two of the three patients survived acute failure of the Medtronic valve.

The chances of survival are increased by clinical awareness, rapid diagnosis, and immediate referral for reoperation. The diagnosis of acute failure of the mechanical valve should be suspected in any patient known to have a mechanical valve who suddenly develops severe cardiac failure. If the patient presents at a hospital where cardiac surgery facilities are not available immediate transfer should be arranged. 
But overreaction is as inappropriate as complacency. The recent acute failures have occurred in well established and widely used mechanical heart valves. ${ }^{56}$ For every reported case of failure there are over 1000 patients with the same types of valves who have not developed this acute complication. Elective reoperation with its inherent mortality and morbidity cannot be recommended. Unfortunately, this unjustifiable course of action has been suggested, sometimes in strong terms, by those who do not fully understand the problem. World wide even worse reactions have been encountered. The media has been used to promote controversy and to achieve political or commercial advantage with no thought for the effects on patients who have artificial heart valves. Similarly, overaggressive legal activity may achieve high litigation awards in the short term at the expense of forcing manufacturers to adopt a negative, defensive attitude to manufacturing and developing valves.

The doctor must report any incident of valve failure both to the manufacturer and to the regulatory authority. Whenever possible the failed valve should be returned for detailed investigation of how it failed. Discussions between manufacturers and regulatory authorities should determine if and when a type of valve should be recalled and should ensure that the fullest information is provided to all cardiac surgeons who implant valves.

The essential requirements are therefore good communication and detailed investigation, and the outcome should be the development of better and safer valves. Certainly, the experience with the failures of the Bjork-Shiley valve has led to a new Bjork-Shiley valve (the Monostrut valve) that is specifically designed to eliminate strut fracture. ${ }^{78}$ Better recording of the performance of artificial valves is also widely recognised as important in improving the design of heart valves. Though reports from individual centres are useful, the results may not be widely representative or capable of extrapolation. An important initiative in Britain is the UK Heart Valve Registry, which was established in 1986 by the Department of Health and Social Security in conjunction with the Society of Cardiothoracic Surgeons of Great Britain and Ireland. This national registry receives data from all centres in the National Health Service and may become the model on which other national and international registries are based.

KEN TAYLOR

British Heart Foundation Professor of

Cardiac Surgery,

Hammersmith Hospital,

London W120HS

1 Dyer C. Six deaths prompt alert over artificial heart valve. Guardian 1988; Sept 17:20.

2 Carpentier A, Chauvaud S, Fabiani JN, et al. Reconstructive surgery of mitral valve incompetence. f Thorac Cardiovasc Surg 1980;79:338-48.

Cosgrove DM, Chavez AM, Lytle BW, et al. Results of mitral valve reconstruction. Circulation 1986;74:82-7.

4 Gersh BJ, Fisher LD, Schaff HV, et al. Issues concerning the clinical evaluation of new prosthetic valves. I Thorac Cardiovasc Surg 1986;91:460-6.

5 Klepetko W, Moritz A, Khunl-Brady G, et al. Implantation of the Duromedics bileaflet cardiac valve prosthesis in 400 patients. Ann Thorac Surg 1987;44:303-9.

6 Antunes MJ, Wessels A, Sadowski RG, et al. Medtronic Hall valve replacement in a third-world population group. 7 Thorac Cardiovasc Surg 1988;95:980-93.

7 Biork VO, Lindblom D. The Monostrut Bjork-Shiley heart valve. $f$ Am Coll Cardiol 1985;6:1142.

8 Thulin LI, Bain WH, Huysmans HH, et al. Heart valve replacement with the Bjork-Shiley Monostrut valve: early results of a multicenter clinical investigation. Ann Thorac Surg 1988;45:164-70.

\section{Seeing the body after death}

\section{Little evidence available but seems to help grieving}

After the war in the Falklands there was debate about whether the bodies of dead servicemen should be returned to Britain. Now attention is focused on retrieving the bodies of the men who died on the Piper Alpha oil rig. Also in the news is the case of Susy Lamplugh, the estate agent who disappeared whose body has never been found. It has been claimed that relatives are helped to grieve if they see the body, but evidence on this is lacking.

The best evidence concerns perinatal deaths. Lewis emphasised the importance of parents seeing and holding a stillborn baby, even if the baby was macerated or disfigured, ${ }^{1}$ and this is now a normal part of obstetric practice. A photograph of the baby may be taken and retained in the case notes so that, even if parents are too distressed to see the baby at the time, they may have a reminder later. Savage argues that parents should perhaps see the baby even if he or she is disfigured because the disfigurement may be perceived as greater by the staff than by the parents. ${ }^{2}$ Their fantasy may be of something worse, and even if the child is severely disfigured the parents may be helped by holding the baby wrapped in a blanket without seeing him or her.

In adult deaths the relatives are often advised not to see the body if death has been violent or disfiguring but rather to remember the person as he or she was in life. Raphael has argued that "not being able to see the body may in itself contribute to the difficulties the bereaved experiences afterwards." ${ }^{3}$ Singh and Raphael interviewed 44 relatives of people killed in a rail disaster: of the 36 who had not seen the body despite being advised to do so, 22 regretted their decision after 18 months compared with only one of the eight who did see the body. ${ }^{+}$It seems worth while for relatives to view the body, but perhaps those who choose to do so are different in their personalities and ability to cope from those who do not. When the family finds it hard to decide it may be helpful - as with stillbirths - to include a photograph of the body in the case notes. Post-traumatic stress disorder might, however, be precipitated by horrifying experiences of seeing mutilated persons, and people should always be prepared as much as possible for what they are to see.

Viewing the body may help not only by showing that the reality is less horrific than the fantasy but also by providing evidence that the dead are dead, giving a physical image of death and giving the bereaved a chance to say "goodbye."

A particular problem arises with children, who used to see bodies after death but now often do not in British culture. Some children are naturally curious but hold back because they sense distress in adults. A child who asks to see a body should probably be allowed to do so, but problems may be created by classmates asking about the experience. The parents should prepare the child by asking questions like: "Have any of your friends been to a funeral?" and "What will you tell them about it?"

Stress also arises in staff who must cope with death, and nurses report that they find dealing with death and dying a major stress. ${ }^{5}$ Rescue workers at disasters may be affected by the sheer scale of the tragedy, and Jones has described the angry reactions of servicemen who recovered the bodies after the mass suicide in Jonestown, Guyana. ${ }^{6}$ Those who give emotional support to these workers experience their own distress. Raphael, a psychiatrist who has contributed much to 